\title{
Climate change, health and wellbeing: challenges and opportunities in NSW, Australia
}

\section{Neil Hime a,b,d, Aditya Vyas ${ }^{a}$, Kishen Lachireddya, Stacey Wyetta Benjamin Scalley and Carlos Corvalana,b,c}

a Environmental Health Branch, Health Protection NSW, NSW Health, Sydney, Australia

b School of Public Health, University of Sydney, NSW, Australia

c Guest Editor, Public Health Research \& Practice, Issue 4, 2018

dCorresponding author: neil.hime@health.nsw.gov.au

\section{Article history}

Publication date: December 2018

Citation: Hime N, Vyas A, Lachireddy K, Wyett S, Scalley B, Corvalan C. Climate change, health and wellbeing: challenges and opportunities in NSW, Australia. Public Health Res Pract. 2018;28(4):e2841824. https://doi.org/10.17061/phrp2841824

\section{Key points}

- Increased frequency and intensity of heatwaves, droughts, floods, bushfires and storm surges are likely to affect health and wellbeing in New South Wales, Australia

- The cumulative indirect impacts of climate change on health through effects on air, water, food and ecosystems are likely to be substantial

- Building adaptive capacity and resilience and mitigating climate change creates opportunities to promote health

\section{Abstract}

The NSW (New South Wales) Climate Change Policy Framework, launched by the NSW Government in 2016, recognises that climate change presents risks to health and wellbeing. Risks to health and wellbeing come from direct impacts of extreme weather events, and from indirect impacts through effects on air, water, food and ecosystems. Responding to these challenges offers an opportunity to protect and promote health by enhancing environmental amenities, and building adaptive capacity and resilience in populations and systems. To develop policy that effectively protects and promotes health in the face of climate change in NSW it is necessary to define the expected impacts of climate change on health and wellbeing in NSW.

\section{Introduction}

In 2016, the New South Wales (NSW) Government launched the NSW Climate Change Policy Framework. ${ }^{1}$ Aspirational long-term objectives of the framework are to achieve net-zero emissions by 2050 and for NSW to be more resilient to a changing climate. Mitigating climate change and increasing resilience to the effects of climate change are crucial missions for improving health. Reducing the effects of climate change on health and wellbeing is one of seven policy directions within the framework. To develop policy actions that effectively and efficiently reduce the impacts of climate change on health and wellbeing it is important to acknowledge the challenges and opportunities that climate change presents for health and wellbeing in NSW.

The NSW Government's Ministry of Health, and public health units in Local Health Districts throughout NSW, have health protection responsibilities. Those responsibilities are met through health promotion, health policy and public health responses to environmental incidents and hazards; this involves working with other agencies with environmental responsibilities. To this end, public health practitioners in environmental health have an obligation to appreciate the impacts that climate change presents to health in NSW. 


\section{The need to understand the impact of climate change on health in NSW}

As this issue of Public Health Research \& Practice highlights, there is substantial evidence that climate change is affecting human health. Even with efforts to mitigate climate change, these impacts will continue for many years because of the inherent inertia in atmospheric and ecological processes that causes climate change to continue. ${ }^{2}$

'Climate change and health' is reported on regularly at the global level. ${ }^{3,4}$ However, global investigations do not provide enough detail about climate change and health in our region on which to base policy appropriate for NSW.

The climate is not only changing in different ways in different regions of the world, but similar changes in climate can be expected to affect health differently depending on determinants such as population health status, climate-human behaviour interactions, and the availability and quality of health and other services. Even among countries with relatively similar disease burdens and health service capacities, climate change may affect health in different ways. For example, it has been postulated that, in the US, climate change may expand the area of dengue fever risk by increasing the area of natural habitat suitable for mosquitoes that can transmit the dengue virus. ${ }^{5}$ However, in Australia, if the range of dengue-transmitting mosquitoes is to expand it is more likely to result from changes in domestic water storage practices (providing water for mosquitoes to breed) in response to an increasing risk of water shortages from more frequent and severe droughts. ${ }^{6}$ This illustrates the importance of local knowledge for predicting climate change risks and developing appropriate policy to address those risks.

\section{Climate change and health and wellbeing in NSW}

Climate change affects health directly through extreme events and indirectly through effects on air, water, food and ecosystems (Figure 1). However, especially in urban environments, the importance of the climate for health and wellbeing may be concealed by modern conveniences. In NSW and elsewhere, amenities such as airconditioning, good-quality housing and public utilities will limit, but not avoid, the health impacts of climate change.

Table 1 provides an indicative rather than an exhaustive list of climate change that is reasonably expected to impact health and wellbeing in NSW. The list was generated using climate projections of the NSW and ACT (Australian Capital Territory) Regional Climate Modelling (NARCliM) Project ${ }^{7}$ (a partnership between government agencies and UNSW Sydney), climate projections of a collaboration between the Bureau of Meteorology and the CSIRO (Commonwealth Scientific and Industrial Research Organisation) ${ }^{8}$, and meteorological trend data from the Bureau of Meteorology.

\section{Direct health and wellbeing impacts}

The incidence of health effects directly related to heat such as heat exhaustion and heat stroke are expected to increase in NSW in line with an increase in the number and severity of heatwaves. The impact of an exceptional heatwave in Sydney and the Hunter region of NSW from 30 January to 6 February 2011 is an example of what can be expected to occur more often in the future. That heatwave resulted in 104 hospital emergency department visits for heat-related health effects. ${ }^{9}$ Health

Table 1. Climate change in $\mathrm{NSW}^{7,8}$ that is likely to impact health and wellbeing

\begin{tabular}{ll}
\hline Predicted climate change in NSW & \\
\hline $\begin{array}{l}\text { More numerous and severe } \\
\text { heatwaves }\end{array}$ & $\begin{array}{l}\text { More than } 20 \text { additional days each year } \\
\text { with a maximum temperature }>35^{\circ} \mathrm{C}\end{array}$ \\
across most of NSW by 2070 \\
More droughts & $\begin{array}{l}\text { Southern NSW is receiving } 10-60 \mathrm{~mm} \\
\text { less rain per decade }\end{array}$
\end{tabular}

More floods

More bushfires

More storm surges
Up to $30 \%$ more autumn rainfall in northern NSW by 2070

More days of severe bushfire risk across NSW by 2070

Sea level along the NSW coast is projected to rise by $0.4-0.7 \mathrm{~m}$ by 2090

\section{Health impacts}

Direct health effects; indirect impacts through air quality, water quality, food quality and ecosystem change

Direct health effects on people who rely on rainfall for their livelihood; indirect impacts through air quality, food quantity and ecosystem change

Direct health effects; indirect impacts through water quality, food quantity and ecosystem change

Direct health effects; indirect impacts through air quality ${ }^{a}$

Direct health effects ${ }^{a}$

Increases in bushfires and storm surges may result in ecosystem change however it is unclear what impact that might have on health in NSW 
Figure 1. Direct and indirect impacts of climate change

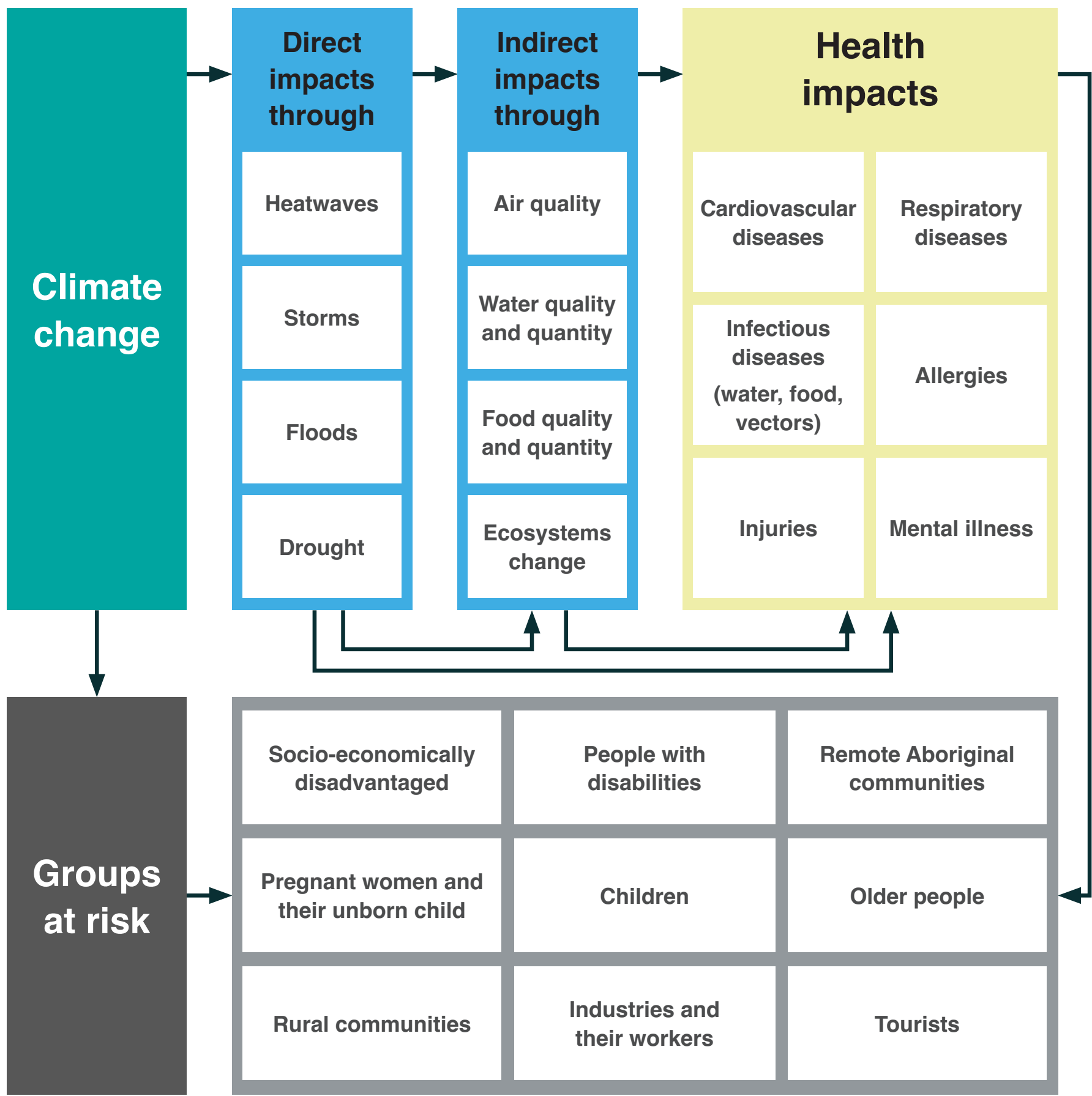

effects defined specifically as heat-related are only a fraction of the health consequences of extreme heat. For example, there is an increased risk of heart attacks during heatwaves due to the cardiovascular stress associated with exposure to high temperatures, especially in the elderly and people with chronic disease. ${ }^{10}$

Increasing periods of drought directly affect the health and wellbeing of farmers and rural communities whose livelihoods depend on regular rainfall. Climate changerelated increases in the frequency and intensity of bushfires and extreme weather events such as floods and coastal storm surges are also likely to have direct impacts on health through injury and the psychological trauma of displacement and property loss.

\section{Indirect health and wellbeing impacts}

Heatwaves can indirectly affect health by increasing the temperature-dependent formation of ground-level ozone, a respiratory irritant generated in the atmosphere from other air pollutants (Figure 2). It has been projected that by 2051-2060, there could be additional deaths in Sydney caused by an increase in ground-level ozone. ${ }^{11}$ 
Figure 2. Ground-level ozone concentration in Sydney is closely associated with daily maximum temperature

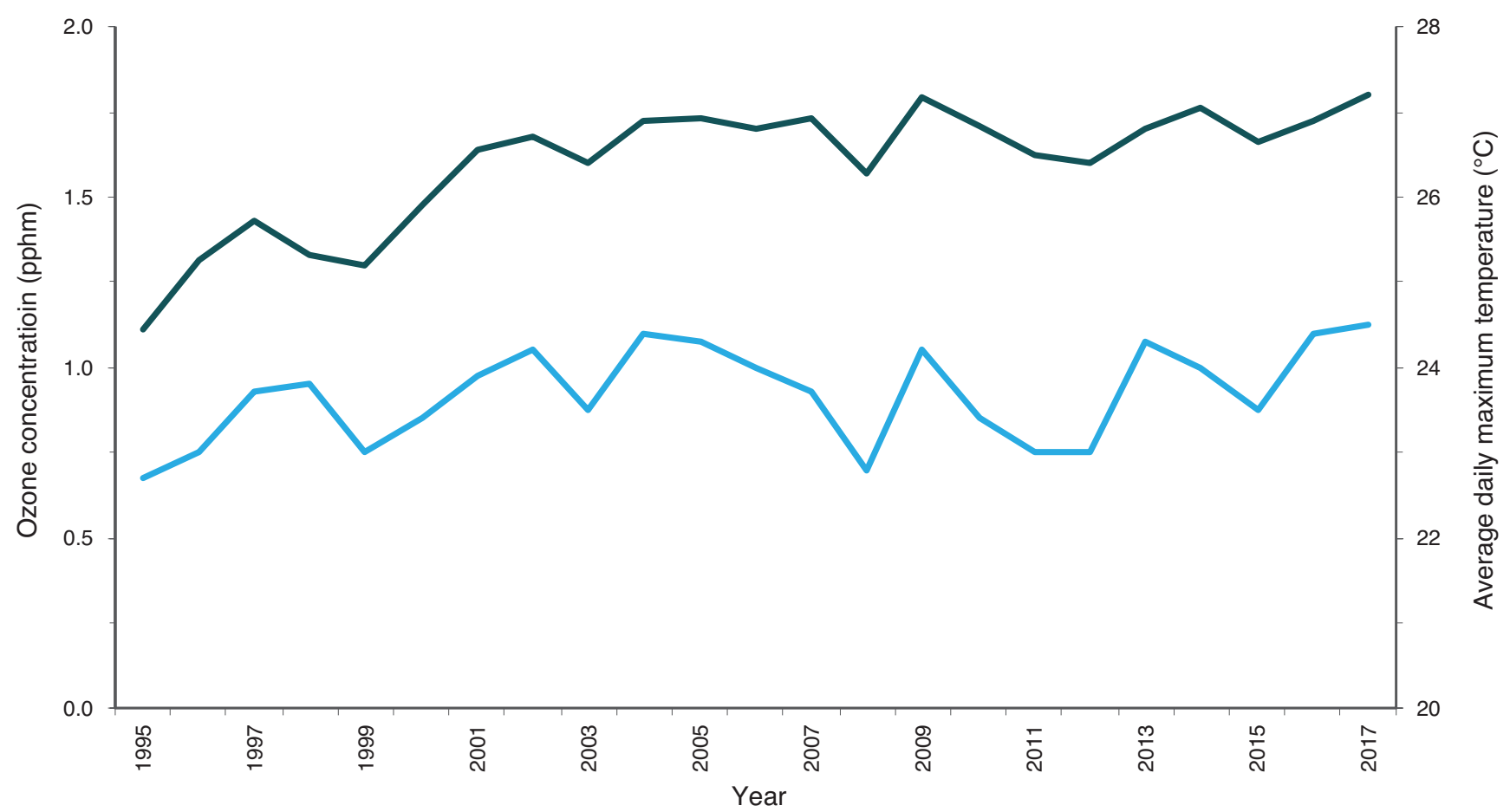

- Ozone concentration (average across metropolitan Sydney)

Average daily maximum temperature (Parramattaa $)$

pphm $=$ parts per hundred million

a The Parramatta weather station is located approximately centrally to the ozone monitoring stations in metropolitan Sydney.

Data sources: NSW Office of Environment and Heritage, and Australian Bureau of Meteorology

Increased heat can also indirectly affect health by increasing the risk of toxic blue-green algal blooms and other waterborne disease, especially when combined with increased nutrient runoff during intense storms and floods. ${ }^{12}$ Increased temperatures also increase rates of food spoilage and the potential for foodborne disease. ${ }^{13}$

Droughts can indirectly affect health by increasing the risk of dust storms and poor air quality associated with those events. ${ }^{14}$ Lower food yields during droughts and floods can decrease nutritional intake and affect health, especially among people who are less able to afford increases in food prices during food shortages. Bushfires can indirectly affect health through the impact of bushfire smoke on air quality. ${ }^{15}$

The extent of the effect on population health in NSW of indirect impacts of climate change, including downstream effects that may arise from ecosystem change, are yet to be realised, but the cumulative burden is likely to be substantial. Climate change has the potential to affect the physical health, livelihoods, prosperity, property, security and social connectedness of people in NSW. These impacts, together with stress and anxiety directly associated with worry about climate change threats, are likely to have major consequences for mental health. ${ }^{16}$

\section{Climate change and opportunities to promote health}

Beyond certain thresholds of severity and duration, decreases in environmental amenity associated with climate change will necessitate increases in adaptive capacity and resilience to prevent significant and widespread impairment of human health. This requires adopting adaptive management processes ${ }^{17}$ within a framework that aims to create multiple societal and environmental benefits. Such a framework needs to be robust so that it can adapt to changing circumstances and alternative developments.

Climate change presents many health challenges but taking action to minimise its impacts through adaptation and mitigation is an opportunity to improve health. In the words of Lewis Mumford, the 20th century American historian and philosopher: "Kites rise against, not with, the wind." Climate change provides an incentive to implement actions that promote health. Examples of adaptive capacity and resilience-building actions with health and wellbeing benefits are: chronic disease prevention and management programs, increasing urban green space, social programs for people who are isolated 
and vulnerable, and making housing more resilient to climate extremes.

Building adaptive capacity and resilience is important, but without climate change mitigation, adaptive capacity could be overwhelmed by a climate that is so extreme that severe and widespread consequences for health are unavoidable. Efforts must be made to mitigate climate change, principally through reductions in greenhouse gas emissions. Health systems, with their energyintensive services, can play a part through efficiency and sustainability practices, and uptake of renewable energy, as described in this issue by Charlesworth et al. ${ }^{18}$ NSW Health is the largest general government energy consumer in NSW, and is actively pursuing initiatives to improve resource efficiency. ${ }^{19}$

Climate change mitigation can also have health and wellbeing co-benefits. For example, reduced use of fossil fuels can reduce other air pollutants such as particulate matter and ozone that have adverse effects on health. ${ }^{20}$ Additionally, less reliance on private vehicles (which predominantly use fossil fuels), and promotion of active and public transport alternatives, promotes physical activity and decreases noncommunicable disease.

Climate change policies provide a mandate for enacting a variety of public health and social programs, but there are many potential barriers to implementation. Complex causal chains between climate change and health will necessitate unfamiliar stakeholders working together. The issue of climate change and health must compete with numerous other health priorities; it may be perceived that climate change is an issue for the far future. There may be reticence to commit resources in the face of uncertainty and the absence of clear, measurable, near-term pay-offs. However, environmental health protection measures are often not predicated on complete understanding of the cause and effect relationship; some knowledge deficit in understanding the extent to which health outcomes are attributable to climate change should not preclude implementing measures likely to have considerable health and social benefits.

Intersectoral action will be required to reduce the health impact of climate change. The principal reason for much of the action on climate change is to avert adverse consequences to human health and wellbeing. Therefore, public health practitioners have an important role to play in promoting and facilitating such action.

\section{Conclusion}

Considering climate change and health in the context of NSW is an important initial step towards taking appropriate action to protect and promote health as our region experiences exceptional climate change. Populations everywhere face challenges related to climate change. Local climate data and projections are a valuable resource to define the important challenges at the jurisdictional level. Local climate change and health research, and international climate change and health literature, are important enablers for jurisdictions to determine what are likely to be the health challenges for their area.

\section{Acknowledgements}

We thank Cameron Webb for his valuable comments about the text related to mosquito-borne viruses.

\section{Peer review and provenance}

Externally peer reviewed, commissioned.

\section{Competing interests}

None declared.

\section{Author contributions}

$\mathrm{NH}$ drafted the manuscript and $\mathrm{AV}, \mathrm{KL}, \mathrm{SW}, \mathrm{BS}$ and $\mathrm{CC}$ reviewed and edited it.

\section{References}

1. Office of Environment and Heritage. NSW climate change policy framework. Sydney: State of NSW and Office of Environment and Heritage; 2016 [cited 2017 Dec 11]. Available from: www.environment.nsw.gov.au/-/media/ $\mathrm{OEH} /$ Corporate-Site/Documents/Climate-change/nswclimate-change-policy-framework-160618.pdf

2. Intergovernmental Panel on Climate Change. Climate change 2014: synthesis report. Contribution of Working Groups I, II and III to the Fifth Assessment Report of the Intergovernmental Panel on Climate Change. Core Writing Team, Pachauri RK, Meyer L, editors. Geneva, Switzerland: IPCC; 2014 [cited 2018 Oct 11]. p.16. Available from: www.ipcc.ch/report/ar5/syr

3. Watts N, Amann M, Ayeb-Karlsson S, Belesova K, Bouley T, Boykoff M, et al. The Lancet Countdown on health and climate change: from 25 years of inaction to a global transformation for public health. Lancet. 2018;391:581-630.

4. Intergovernmental Panel on Climate Change. Summary for policymakers. In: Climate change 2014: impacts, adaptation, and vulnerability. Part A: global and sectoral aspects. Contribution of Working Group II to the fifth assessment report of the Intergovernmental Panel on Climate Change. Field CB, Barros VR, Dokken DJ, Mach $\mathrm{KJ}$, Mastrandrea MD, Bilir TE, et al, editors. Cambridge and New York: Cambridge University Press; 2014. pp. 1-32. Available from: www.ipcc.ch/report/ar5/wg2 
5. Butterworth MK, Morin CW, Comrie AC. An analysis of the potential impact of climate change on dengue transmission in the southeastern United States. Environ Health Perspect. 2017; 125:579-85.

6. Kearney M, Porter WP, Williams C, Ritchie S, Hoffmann AA. Integrating biophysical models and evolutionary theory to predict climatic impacts on species' ranges: the dengue mosquito Aedes aegypti in Australia. Func Ecol. 2009;23:528-38.

7. NSW Office of Environment and Heritage. AdaptNSW understanding and adapting to climate change impacts in New South Wales. Sydney: State of New South Wales and Office of Environment and Heritage [cited 2017 Dec 10]. Available from: climatechange.environment.nsw. gov.au

8. CSIRO and Bureau of Meteorology. Climate Change in Australia. Canberra: Commonwealth Scientific and Industrial Research Organisation; 2015-2017 [cited 2017 Nov 29]. Available from: www.climatechangeinaustralia. gov.au/en/

9. Schaffer A, Muscatello D, Broome R, Corbett S, Smith W. Emergency department visits, ambulance calls, and mortality associated with an exceptional heat wave in Sydney, Australia, 2011: a time-series analysis. Environ Health. 2012;11(1):3

10. Kenney WL, Craighead DH, Alexander LM. Heat waves, aging, and human cardiovascular health. Med Sci Sports Exerc. 2014;46(10):1891-9.

11. Physick W, Cope M, Lee S. The impact of climate change on ozone-related mortality in Sydney. Int J Environ Res Public Health. 2014;11(1):1034-48.

12. Mansour SA. Impact of climate change on air and water borne diseases. Air Water Borne Diseases. 2013;3:e126.

13. Britton E, Hales S, Venugopal K, Baker MG. Positive association between ambient temperature and salmonellosis notifications in New Zealand, 1965-2006. Aust N Z J Public Health. 2010;34(2):126-9.
14. Jayaratne ER, Johnson GR, McGarry P, Cheung HC, Morwawska L. Characteristics of airborne ultrafine and coarse particles during the Australian dust storm of 23 September 2009. Atmos Environ. 2011;45(24):39964001.

15. Johnston F, Hanigan I, Henderson S, Morgan G, Bowman D. Extreme air pollution events from bushfires and dust storms and their association with mortality in Sydney, Australia 1994-2007. Environ Res. 2011;111(6):811-6.

16. Clayton S, Manning CM, Krygsman K, Speiser M. Mental health and our changing climate: impacts, implications, and guidance. Washington DC: American Psychological Association and ecoAmerica; 2017 [cited 2018 Nov 15]. Available from: www.apa.org/news/press/ releases/2017/03/mental-health-climate.pdf

17. Marinucci GD, Luber G, Uejio CK, Saha S, Hess JJ. Building resilience against climate effects - a novel framework to facilitate climate readiness in public health agencies. Int J Environ Res Public Health. 2014;11(6):6433-58.

18. Charlesworth KE, Stewart GJ, Sainsbury P. Addressing the carbon footprint of health organisations: eight lessons for implementation. Public Health Res Pract. 2018;28(4):e2841829.

19. NSW Health. Resource efficiency strategy 2016 to 2023. Sydney: NSW Health; 2016 [cited 2018 Oct 11]. p. 1. Available from: www.health.nsw.gov.au/assets/ Publications/resource-efficiency-strategy.pdf

20. West JJ, Smith SJ, Silva RA, Naik V, Zhang Y, Adelman Z, et al. Co-benefits of mitigating global greenhouse gas emissions for future air quality and human health. Nature Clim Change. 2013;3(10):885-9.

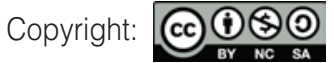

(C) 2018 Hime et al. This article is licensed under the Creative Commons Attribution-NonCommercial-ShareAlike 4.0 International Licence, which allows others to redistribute, adapt and share this work non-commercially provided they attribute the work and any adapted version of it is distributed under the same Creative Commons licence terms. See: www.creativecommons.org/licenses/by-nc-sa/4.0/ 